\title{
Smoking Habits of 800,000 American Men and Women in Relation to Their Occupations
}

\author{
Steven D. Stellman, PhD, Paolo Boffetta, MD, and Lawrence Garfinkel, MA
}

\begin{abstract}
The distribution of cigarette smoking (as well as of cigar and pipe smoking in men) by occupation was examined in over 800,000 men and women age 45-70 who were enrolled in the American Cancer Society's prospective study in 1982. Striking variations were seen for men-less striking variations for women. Smoking rates were significantly higher in groups exposed to a number of occupational hazards, compared to groups not so exposed. A considerable amount of variation is related to social class, but some individual occupations exhibit notably high (law enforcement) or low (clergy) smoking rates.

This information can be quite useful in planning morbidity or mortality studies of specific occupational groups or in analyzing data from existing studies.
\end{abstract}

Key words: cigarette smoking, job categories, occupational exposures, prospective studies, epidemiology

\section{INTRODUCTION}

Cigarette smoking in the United States is a class-related behavior, just as employment status is. It stands to reason, therefore, that smoking will not be equally distributed across occupations but will be higher in some and lower in others. Attempts to develop universal rules are probably futile, because of the peculiarities of how smoking patterns developed, particularly in the two sexes. For instance, in an earlier study based upon the National Center for Health Statistics Health Interview Survey, Stellman and Stellman [1981] found that men in higher income and educational groups smoked less while men in lower groups smoked more. But even so broadly simple a generalization did not hold true for women. Those women least likely to smoke were teachers and household workers, groups at opposite ends of the social spectrum.

Changing behavior patterns, especially with regard to smoking cessation, make necessary constant reassessment of current patterns from fresh surveys, so that outof-date smoking patterns are not inadvertently employed in interpretation of current occupational morbidity and mortality.

American Cancer Society, New York, NY.

Address reprint requests to Steven D. Stellman, American Cancer Society, 1180 Avenue of the Americas, New York, NY 10001.

Accepted for publication July 28, 1987.

(C) 1988 Alan R. Liss, Inc. 
In this paper we present a synopsis of cross-sectional smoking behavior observed at baseline in the Cancer Prevention Study-II (CPS-II), a prospective study of 1.2 million men and women begun by the American Cancer Society in 1982. This analysis differs from the companion study by NIOSH [Brackbill et al, 1988] in a number of important respects, which should be understood clearly in order to draw proper comparisons and contrasts between the two studies. First, the NIOSH study is taken from a probability sample of the noninstitutionalized U.S. population, and therefore may be considered representative of that population. CPS-II is a volunteerorganized and -selected population. The subjects are friends, neighbors, and relatives of CPS-II volunteers and therefore reflect the social and ethnic backgrounds of people who volunteer their services to the American Cancer Society. This specifically manifests itself in higher average educational levels and extends to variables which are correlates of education. Second, the CPS-II subjects were deliberately chosen to be older adults, with the median age 57. Third, they are known to be healthier initially, and have already been observed to experience significantly lower death rates than the general population after two years of follow-up. One reason for this favorable mortality is that their smoking habits are lower than the American average, as we have reported recently [Stellman and Garfinkel, 1986].

These differences do not, however, mean that this population has nothing to offer a smoking-occupation study. We have reported, for instance, that adjustment for age and educational level produces smoking distributions similar to national ones [Stellman and Garfinkel, 1986]. In addition, the comparisons offered below are nearly all internal to this study group; biases arising from systematic differences with the general population tend to cancel out in such comparisons. And finally, CPS-II subjects comprise over $1.5 \%$ of all American adults age 45 and over and therefore constitute an important subgroup in their own right, well worthy of characterization and generalization.

In this analysis we will attempt to answer two questions: Which occupations have the highest and which the lowest percentages of smokers? What is the distribution of smoking habits among workers exposed to specific occupational hazards, in comparison to workers not so exposed?

\section{MATERIALS AND METHODS}

The data in this study are from the baseline questionnaire of the American Cancer Society's CPS-II, details of which have previously been reported [Stellman and Garfinkel, 1986; Garfinkel and Stellman, 1986]. From September through November, 1982, more than 77,000 volunteer "researchers" enrolled 509,000 men and 677,000 women in all 50 states, the District of Columbia, and Puerto Rico. The subjects completed a four-page confidential questionnaire on history of cancer and other diseases; body weight and height; exercise; occupations and occupational exposures; and personal habits such as drinking, smoking, and diet.

The logistics of collecting this quantity of information, especially through the efforts of volunteers, placed constraints on the number and type of specific data items which could be asked and for which reasonably accurate answers could be expected. The first constraint was that this mostly older population, which included many subjects in their $70 \mathrm{~s}$ and $80 \mathrm{~s}$, be capable of filling out a detailed questionnaire without help. Therefore the typeface could not be too small for persons of this age to read 
comfortably. The length of the questionnaire had to balance our desire to collect as much information as possible with the patience of the subjects in filling it out; we did not wish to burden our subjects with a questionnaire so long they might decide midway to throw it out. On the other hand, it could not be so short as to be useless. The questions had to be worded simply and unambiguously, since there was to be no second chance to resolve conflicting information. And it had to cover a specific array of topics thought to be related to development of cancer, as this was the primary purpose of the study.

The final questionnaire was arrived at through an extensive series of pretests in 13 cities, with over 3,500 subjects in real-life walk-throughs of procedures. The questionnaire was printed on a single $11 \times 17$-inch sheet that was folded in half to form a four-page booklet. There were male and female versions of the questionnaire, which differed in content of some sections, such as reproductive history and military service. The principal demographic and health history sections were identical for men and women, as were the occupational sections.

\section{Selection of Subjects}

The primary purpose of this analysis is to examine the smoking habits of study subjects who work or have worked at different occupations, in order to develop some feeling for the type of information which needs to be collected in occupational studies. Data from very old subjects is unlikely to be informative in this respect, and in fact could turn out to be misleading, because of cohort-related changes in smoking and because of a survivorship effect. Older persons (say in their 70 s and above) belong to cohorts which had considerably different smoking patterns than present-day workers, both with regard to age of initiation, quantity, and type of product smoked. In addition, the selectively higher death rates among smokers, especially of greater quantities of cigarettes (a variable related to occupation, as shown below), tends to reduce the percentage of smokers in this cross-sectionally examined population. Similar arguments may be made for especially hazardous occupations.

Therefore, we restricted our analysis to a population which is presently or recently of working age-namely, men and women ages $45-70$, inclusive. Percent distributions given below are not adjusted for age. Given the major differences between the CPS-II population and the general population with respect to education and other socioeconomic variables, it was felt that adjustment to some artificial standard, even that of the U.S. population, would invite inapt comparisons.

\section{Classification of Occupations}

In a study of this type, it is impossible to predict in advance what the distribution of stated occupations will be. Even if they were known, the variety is so great in a population of over a million people that a uniform coding scheme which covers every actual response is impossible. Even if one could be developed, it would probably be useless for epidemiologic analysis, because there would be a large number of exotic job titles stated by only one or two people. For this reason, use of standard five-digit SIC classifications was out of the question. First, because the questionnaire was selfadministered, it was to be expected that a large number of responses would be ambiguous and unassignable to specific categories (for instance, to question Q1 many people answered simply "Sales" or "Manager" without specifying whether they were involved in heavy industry or retail trade). And second, to improve efficiency and 
reduce both costs and errors, an intermediate coding step was dispensed with; all data items including occupation were entered directly by the key operators, necessitating development of a special operator-machine interface.

\section{Occupational Coding}

The section of the questionnaire entitled "occupations" is reproduced in Figure 1.

The questionnaire was structured in the anticipation that many persons would list their present occupation as "retired." This was in fact observed. In the questions displayed in Figure 1, Q1 refers to current occupation, Q2 to previous occupation if now retired, and Q3 to longest job held.

The occupation codes were determined directly during the data entry step. A preliminary manual tally of several thousand documents identified a large number of similar job titles which fell naturally into about 15 different broad categories. Each such category had one or more related occupations designated within it. These rubrics appear in the tables of smoking distributions given below. To minimize confusion, the same set of two-digit codes was used for men and for women. Each of the nearly 200 separate jobs which comprised the final categories was assigned a three-letter mnemonic code (eg, LAW for lawyer, BOO for bookkeeper). The data-entry operators were trained (and closely monitored by supervisory staff and by us) to enter the appropriate three-letter codes as responses to Qs 1, 2, and 3. This code was immediately translated by the data entry computer to the corresponding two-digit occupational code. After data entry was complete for the entire 1.2 million subjects, occupational codes were checked again by our own quality control staff.

For the present analysis we were most interested in the subject's current occupation, as reported in Q1. In the tables which follow, the majority of subjects (76.0\% of males and $66.5 \%$ of females) were categorized according to Q1 (current occupation) and nearly all the rest according to Q2 (last occupation if retired). A small number of subjects ( $0.1 \%$ of men and $0.8 \%$ of women) had no valid occupation in Q1 or 2 but did have one in Q3 (other than job held for the longest period of time) and were assigned to that job category. Subjects who responded only that they were retired, disabled, unemployed, or a housewife were not included in these analyses. Final categorization of subjects was summarized according to the preceding scheme as a single variable, "Job."

\section{Exposures}

Each subject could check off any of 12 "exposures" to the following occupational hazards: asbestos; chemicals, acids, or solvents; coal tar pitch or asphalt; coal

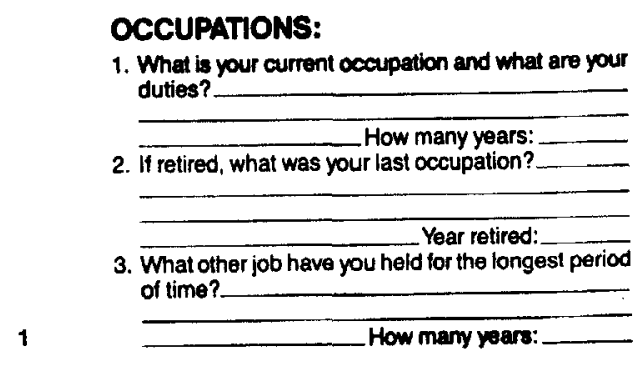

Fig. 1. "Occupations" section of questionnaire. 
or stone dust; gasoline exhaust; diesel engine exhaust; dyes; formaldehyde; pesticides or herbicides; textile fibers or dusts; wood dust; and ionizing radiation. For the present analysis, reported exposure to coal tar, pitch, or asphalt was combined with exposure to chemicals, acids, and solvents, and gasoline and diesel exhaust exposures were combined, for a total of ten named exposures.

\section{RESULTS}

The age distribution of our study population is given in Table I. There were 393,847 male and 478,214 female subjects, or about $72 \%$ of the entire CPS-II population (those excluded being primarily above the age of 70 ).

Table II shows the distribution of job categories for men and Table III that for women, in response to each of the three questions: Q1 (current job), Q2 (last job if retired), and Q3 (job held longest). In this study we will report smoking information only for jobs mentioned by at least 100 subjects.

In the last column of Tables II and III, labeled "job," is shown the number of men or women assigned to the specific job categories according to the above algorithm. Those lifetime occupations with the greatest numbers of subjects are listed first. For brevity, only one- or two-word job titles are given. This is sufficient for many occupational categories (eg, plumber, painter). Categories which contain several different but related job titles are listed in appendix $I$.

It is worthwhile to note the substantial numbers of persons available for study in blue-collar occupations even in this highly selected population. For instance, among men there were 1,415 plumbers, 1,263 painters, and 2,468 "factory workers." As one might expect, female occupations were dominated by office workers $(60,063)$, educators $(43,411)$, sales persons $(36,968)$, and nurses $(25,016)$, but there were also 896 doctors and 1,944 waitresses. Thus, by dint of its sheer magnitude, this population spans a broad range of socioeconomic categories.

The distribution of smoking habits among subjects in each occupational group is reported for males in Table IV and for females in Table V. Occupations with the greatest percentages of life-long nonsmokers are listed first. These two tables also each contain a column giving the average number of cigarettes smoked per day by current smokers.

Important differences between occupational groups can immediately be seen. For instance, among men the groups with the highest proportions of lifelong nonsmokers are clergymen $(43.2 \%)$, farmers $(39.5 \%)$, educators $(35.4 \%)$, and physicians $(32.0 \%)$, while the highest percentage of current heavy smokers (pack-and-a-

TABLE I. Age Distribution of Male and Female Study Subjects

\begin{tabular}{lrrrr} 
& \multicolumn{2}{c}{ Males } & \multicolumn{2}{c}{ Females } \\
\cline { 2 - 4 } Age group & \multicolumn{1}{c}{ No. } & $\%$ & No. & $\%$ \\
\hline $45-49$ & 68,830 & 17.5 & 92,076 & 19.3 \\
$50-54$ & 87,119 & 22.1 & 106,286 & 22.2 \\
$55-59$ & 91,339 & 23.2 & 108,015 & 22.6 \\
$60-64$ & 79,432 & 20.2 & 92,182 & 19.3 \\
$65-70$ & 67,127 & 17.0 & 79,655 & 16.7 \\
Total & 393,847 & 100.0 & 478,214 & 100.1 \\
\hline
\end{tabular}


TABLE II. Number of Male Subjects Reporting Specific Occupations on Individual Questions Q1, Q2, and Q3 and Total Number Classified in Each Lifetime Occupational Category (Job)*

\begin{tabular}{|c|c|c|c|c|}
\hline & Q1 & Q2 & Q3 & Job \\
\hline Manager & 50,420 & 13,361 & 21,858 & 59,388 \\
\hline Sales & 25,886 & 7,788 & 22,280 & 31,034 \\
\hline Engineer & 16,696 & 5,340 & 9,815 & 20,328 \\
\hline Teacher & 17,722 & 4,044 & 9,512 & 20,226 \\
\hline Farmer & 14,553 & 3,843 & 11,572 & 16,782 \\
\hline Executive & 10,072 & 2,132 & 2,603 & 11,526 \\
\hline Real estate & 9,671 & 2,062 & 3,326 & 11,155 \\
\hline Automotive & 7,961 & 3,431 & 8,164 & 10,120 \\
\hline Doctor & 6,703 & 827 & 1,073 & 7,240 \\
\hline Driver of truck or other vehicle & 5,403 & 2,433 & 5,859 & 6,938 \\
\hline Bookkeeper & 5,224 & 1,585 & 3,756 & 6,335 \\
\hline Lawyer & 4,967 & 477 & 1,143 & 5,256 \\
\hline Construction & 4,183 & 1,569 & 3,745 & 5,212 \\
\hline Electrician & 4,049 & 1,656 & 2,739 & 5,180 \\
\hline Office clerical & 4,048 & 1,523 & 3,136 & 5,039 \\
\hline Woodworker & 3,567 & 1,757 & 3,677 & 4,668 \\
\hline Maintenance & 3,662 & 1,312 & 988 & 4,529 \\
\hline Clergy & 4,048 & 706 & 1,527 & 4,481 \\
\hline Machinist & 3,284 & 1,794 & 3,591 & 4,448 \\
\hline Foreman & 3,336 & 1,589 & 1,733 & 4,435 \\
\hline Pharmacist, chemist, mortician & 3,382 & 863 & 1,918 & 3,938 \\
\hline Postal service & 2,399 & 2,010 & 1,239 & 3,670 \\
\hline Banking & 2,933 & 860 & 1,627 & 3,538 \\
\hline Technician: lab, therapy, X-ray & 2,843 & 896 & 2,177 & 3,430 \\
\hline Law enforcement & 2,348 & 1,759 & 1,855 & 3,153 \\
\hline Civil servant & 1,553 & 1,622 & 1,413 & 2,566 \\
\hline Factory worker & 1,700 & 1,203 & 3,400 & 2,468 \\
\hline Military & 663 & 6,021 & 23,624 & 2,440 \\
\hline Dentistry & 2,225 & 190 & 166 & 2,354 \\
\hline Writer, editor & 1,521 & 387 & 1,211 & 1,757 \\
\hline Domestic service & 1,402 & 560 & 448 & 1,744 \\
\hline Fireman & 1,124 & 916 & 746 & 1,596 \\
\hline Food preparation & 1,157 & 717 & 1,856 & 1,591 \\
\hline Welder & 1,090 & 674 & 1,296 & 1,525 \\
\hline Plumber & 1,125 & 440 & 719 & 1,415 \\
\hline Painter & 966 & 462 & 837 & 1,263 \\
\hline Railroad worker & 621 & 780 & 1,067 & 1,166 \\
\hline Steel mill operative & 652 & 656 & 853 & 1,082 \\
\hline Photographer & 846 & 337 & 661 & 1,035 \\
\hline Architect & 930 & 144 & 389 & 1,027 \\
\hline Reautician, barber & 760 & 167 & 593 & 851 \\
\hline Miner & 528 & 383 & 792 & 770 \\
\hline Social worker & 583 & 150 & 330 & 676 \\
\hline Assembler (in factory) & 534 & 191 & 488 & 654 \\
\hline Sewer, stitcher & 469 & 270 & 703 & 642 \\
\hline Other hospital workers & 464 & 178 & 245 & 574 \\
\hline Data entry & 438 & 102 & 235 & 507 \\
\hline Heavy equipment operator & 353 & 161 & 239 & 453 \\
\hline Nurse & 206 & 70 & 106 & 241 \\
\hline Laborer & 193 & 82 & 228 & 237 \\
\hline Telephone operator & 177 & 92 & 146 & 235 \\
\hline Aide (teacher's, day care) & 169 & 61 & 68 & 199 \\
\hline Shipyard worker & 96 & 49 & 172 & 131 \\
\hline Waiter, waitress & 67 & 29 & 138 & 85 \\
\hline
\end{tabular}

*Table does not include: subjects who described themselves only as "retired," "disabled," or "housewife"; subjects who mentioned only occupations not included in the appendix; or any occupations mentioned by fewer than 100 men. See Appendix I for fuller listing of occupational titles. 
TABLE III. Number of Female Subjects Reporting Specific Occupations on Individual Questions Q1, Q2, and Q3 and Total Number Classified in Each Lifetime Occupational Category (Job)*

\begin{tabular}{|c|c|c|c|c|}
\hline & Q1 & Q2 & Q3 & Job \\
\hline Office clerical & 43,371 & 20,607 & 58,696 & 60,063 \\
\hline Teacher & 30,246 & 17,558 & 25,626 & 43,411 \\
\hline Sales & 26,753 & 13,426 & 29,565 & 36,968 \\
\hline Nurse & 18,944 & 8,042 & 13,161 & 25,016 \\
\hline Manager & 17,207 & 6,485 & 8,290 & 21,996 \\
\hline Bookkeeper & 11,546 & 5,870 & 11,726 & 16,129 \\
\hline Food preparation & 4,258 & 2,469 & 3,395 & 6,111 \\
\hline Real estate & 4,501 & 1,358 & 2,176 & 5,583 \\
\hline Aide (teacher's, day care) & 3,086 & 875 & 1,759 & 3,775 \\
\hline Beautician, barber & 2,122 & 1,380 & 2,216 & 3,148 \\
\hline Banking & 2,423 & 889 & 2,762 & 3,090 \\
\hline Factory worker & 1,453 & 1,938 & 5,205 & 2,999 \\
\hline Technician: lab, therapy, X-ray & 2,105 & 1,154 & 2,975 & 2,996 \\
\hline Social worker & 2,164 & 1,050 & 1,754 & 2,949 \\
\hline Sewer, stitcher & 1,571 & 1,425 & 2,250 & 2,631 \\
\hline Other hospital workers & 1,738 & 823 & 1,787 & 2,343 \\
\hline Waiter, waitress & 1,089 & 1,093 & 4,421 & 1,944 \\
\hline Executive & 1,335 & 381 & 486 & 1,629 \\
\hline Assembler (in factory) & 1,084 & 542 & 1,077 & 1,503 \\
\hline Farmer & 861 & 568 & 873 & 1,333 \\
\hline Data entry & 939 & 393 & 1,152 & 1,220 \\
\hline Writer, editor & 876 & 393 & 1,221 & 1,152 \\
\hline Postal service & 778 & 403 & 324 & 1,093 \\
\hline Domestic service & 854 & 294 & 474 & 1,082 \\
\hline Telephone operator & 603 & 557 & 2,836 & 1,030 \\
\hline Driver of truck or other vehicle & 797 & 259 & 524 & 1,006 \\
\hline Doctor & 702 & 245 & 388 & 896 \\
\hline Civil servant & 497 & 526 & 932 & 895 \\
\hline Machinist & 555 & 458 & 677 & 884 \\
\hline Maintenance & 475 & 158 & 154 & 595 \\
\hline Pharmacist, chemist, mortician & 365 & 212 & 548 & 520 \\
\hline Clergy & 384 & 110 & 147 & 457 \\
\hline Engineer & 365 & 97 & 220 & 431 \\
\hline Automotive & 303 & 180 & 338 & 435 \\
\hline Dentistry & 256 & 203 & 544 & 419 \\
\hline Lawyer & 277 & 105 & 192 & 361 \\
\hline Electrician & 188 & 182 & 316 & 325 \\
\hline Law enforcement & 211 & 118 & 207 & 289 \\
\hline Steel mill operative & 106 & 155 & 556 & 238 \\
\hline Photographer & 153 & 79 & 222 & 215 \\
\hline Military & 39 & 173 & 520 & 161 \\
\hline Architect & 112 & 49 & 120 & 153 \\
\hline Construction & 115 & 40 & 63 & 142 \\
\hline Painter & 100 & 32 & 96 & 124 \\
\hline
\end{tabular}

*Table does not include: subjects who described themselves only as "retired," "disabled," or "housewife"; subjects who mentioned only occupations not included in the appendix; or any occupations mentioned by fewer than 100 women. See Appendix I for fuller listing of occupational titles. 


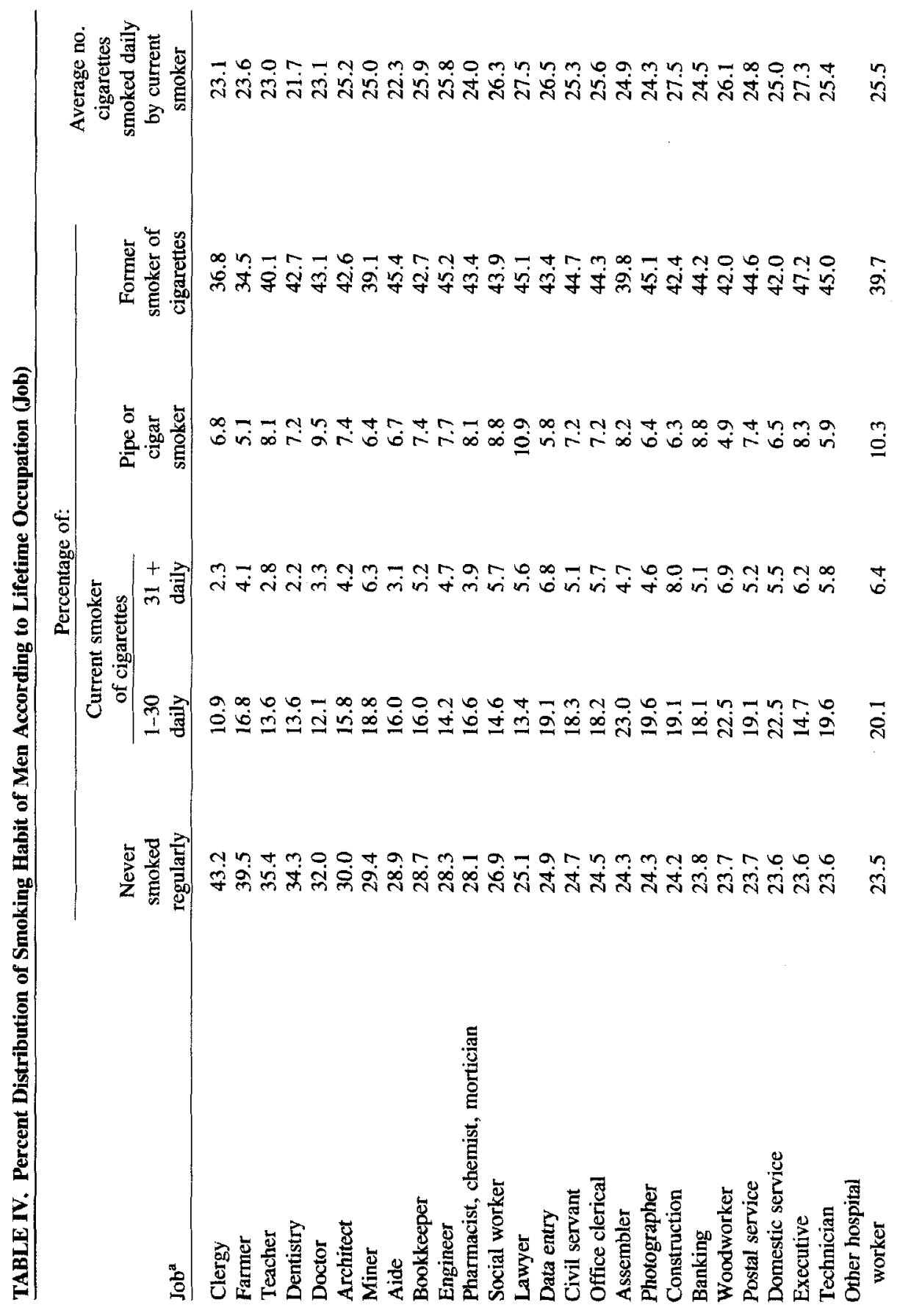


m m

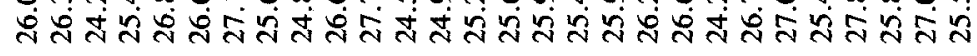

ю

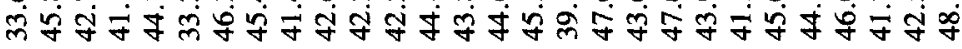

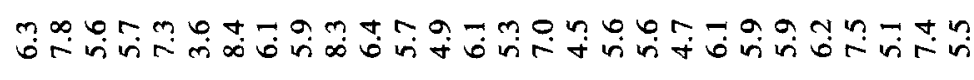

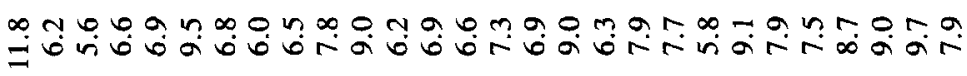

च

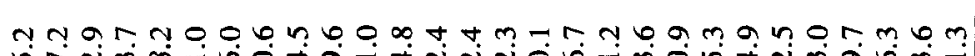

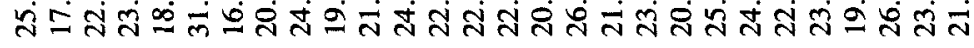

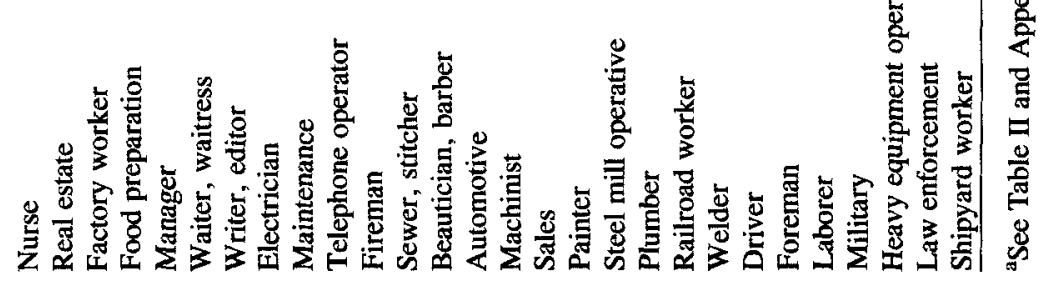




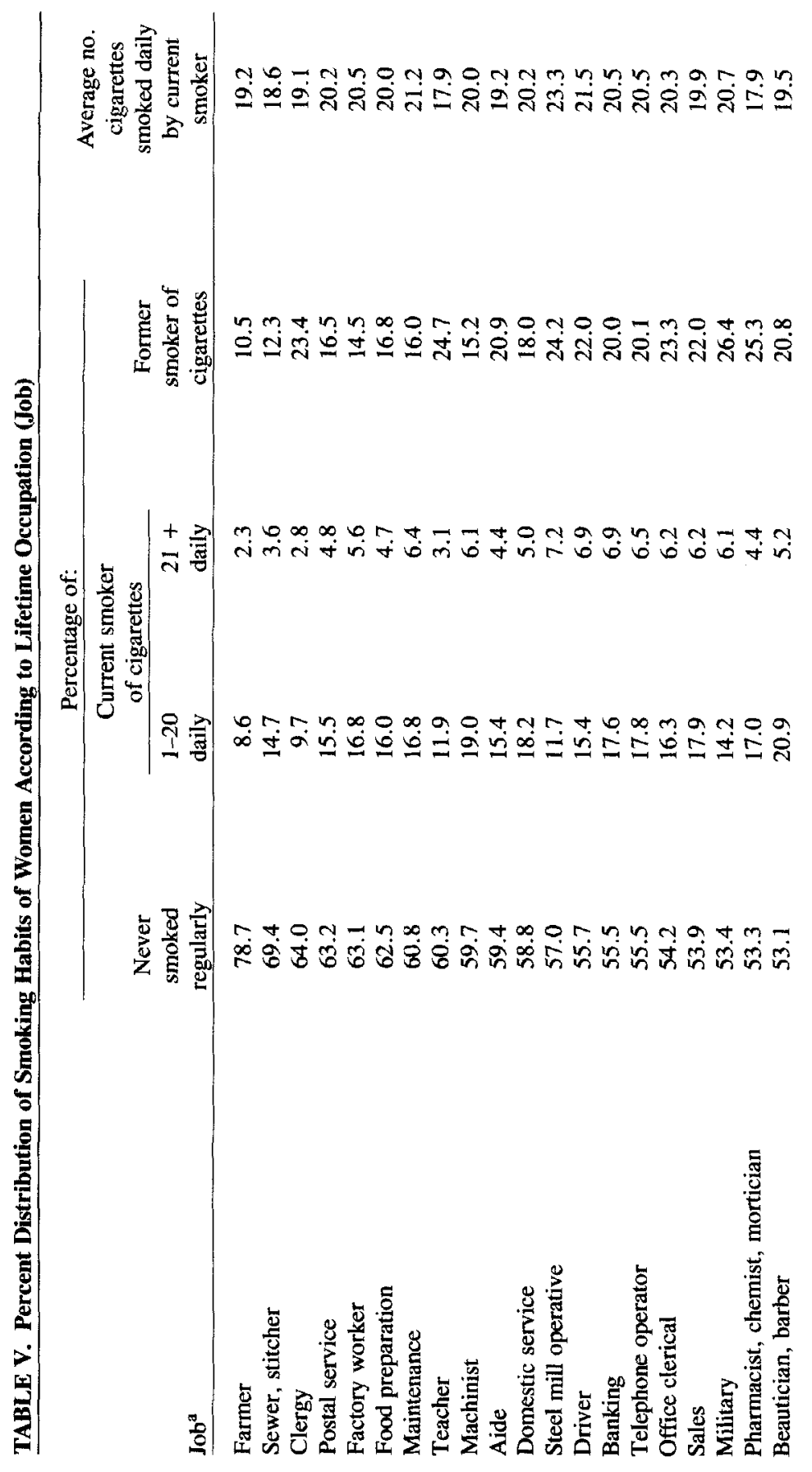




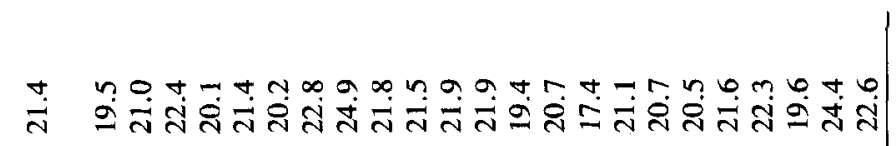

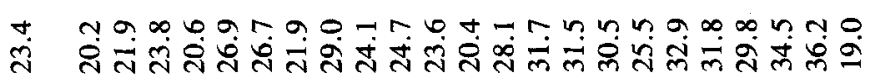

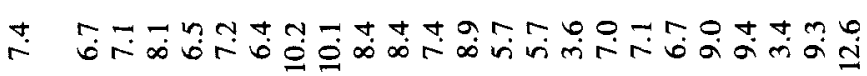

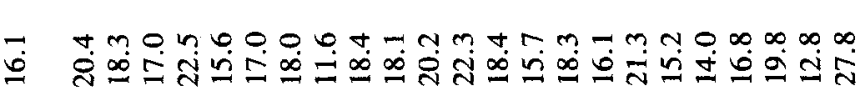

m

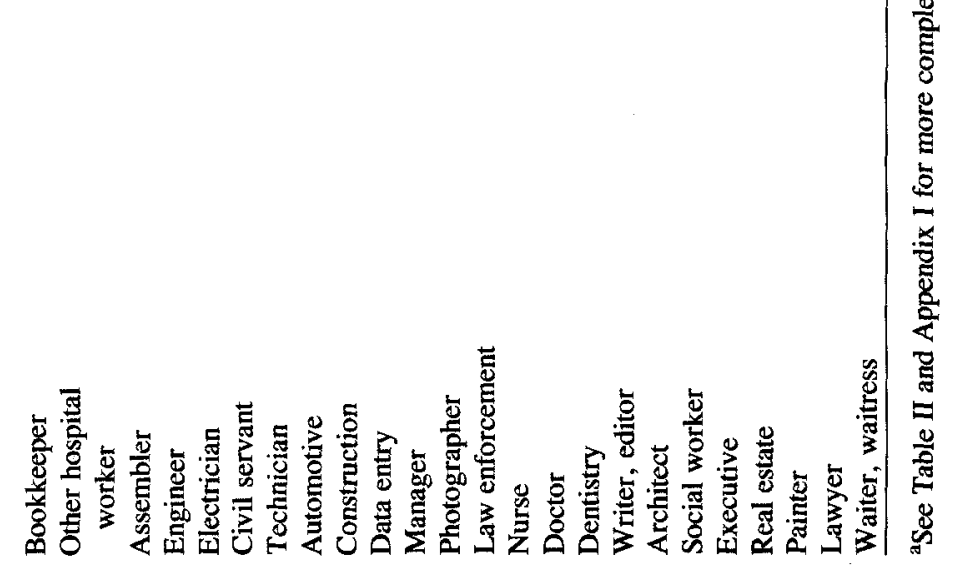


half or more per day) are male nurses $(11.8 \%)$, law-enforcement officers $(9.7 \%)$, and waiters $(9.5 \%)$.

The female groups with the highest rate of life-long nonsmoking are farmers $(78.7 \%)$, and those in sewing trades $(69.4 \%)$, while the heaviest smokers (over a pack daily) were waitresses $(12.6 \%)$ and women in automotive and construction industries. Women in the latter group of smokers also consumed the greatest number of cigarettes per day, 24.9 .

Table VI displays the distribution of smoking habits for men according to their self-described regular exposure to ten occupational hazards. The exposure rates ranged from $2.8 \%$ exposed to various dyes, to $29.4 \%$ of all men in the study reporting

TABLE VI. Percent Distribution of Smoking Habits Among Men According to Occupational Exposures (Percent Exposed or Not Exposed Shown in Parentheses)

\begin{tabular}{|c|c|c|c|c|c|c|}
\hline \multirow[b]{3}{*}{$\begin{array}{l}\text { Exposed to } \\
\text { (No) }\end{array}$} & \multicolumn{5}{|c|}{ Percentage of } & \multirow{3}{*}{$\begin{array}{c}\text { Average no. } \\
\text { cigarettes } \\
\text { smoked } \\
\text { daily by } \\
\text { current } \\
\text { smoker } \\
\text { (c/day) } \\
\end{array}$} \\
\hline & \multirow{2}{*}{$\begin{array}{c}\text { Never } \\
\text { smoked } \\
\text { regularly }\end{array}$} & \multicolumn{2}{|c|}{$\begin{array}{c}\text { Current smoker } \\
\text { of cigarettes }\end{array}$} & \multirow{2}{*}{$\begin{array}{c}\text { Pipe or } \\
\text { cigar } \\
\text { smoker }\end{array}$} & \multirow{2}{*}{$\begin{array}{l}\text { Former } \\
\text { smoker } \\
\text { of } \\
\text { cigarettes }\end{array}$} & \\
\hline & & $\begin{array}{r}1-30 \\
\text { daily } \\
\end{array}$ & $\begin{array}{l}31+ \\
\text { daily }\end{array}$ & & & \\
\hline \multicolumn{7}{|l|}{ Asbestos } \\
\hline Yes (8.4) & 19.1 & 20.2 & 7.3 & 6.1 & 47.3 & $26.9^{\mathrm{a}}$ \\
\hline No (91.6) & 25.8 & 17.7 & 5.8 & 7.2 & 43.4 & 25.7 \\
\hline \multicolumn{7}{|c|}{ Chemicals or coal tar pitch } \\
\hline Yes (25.2) & 22.2 & 20.1 & 6.9 & 6.4 & 44.5 & $26.4^{a}$ \\
\hline No $(74.8)$ & 26.0 & 17.5 & 5.6 & 7.3 & 43.5 & 25.6 \\
\hline \multicolumn{7}{|c|}{ Coal or stone dust } \\
\hline Yes $(8.8)$ & 19.0 & 21.4 & 7.4 & 6.2 & 45.9 & $26.4^{\mathrm{a}}$ \\
\hline No $(91.2)$ & 25.9 & 17.7 & 5.8 & 7.2 & 43.4 & 25.7 \\
\hline \multicolumn{7}{|c|}{ Gasoline or diesel exhaust } \\
\hline Yes (29.4) & 22.5 & 20.1 & 6.9 & 6.4 & 44.0 & $26.3^{\mathrm{a}}$ \\
\hline No $(70.6)$ & 26.3 & 17.4 & 5.5 & 7.4 & 43.5 & 25.6 \\
\hline \multicolumn{7}{|l|}{ Dyes } \\
\hline Yes $(2.8)$ & 20.8 & 21.7 & 6.7 & 6.4 & 44.4 & 25.6 \\
\hline No $(97.2)$ & 25.7 & 17.7 & 5.8 & 7.2 & 43.6 & 25.8 \\
\hline \multicolumn{7}{|l|}{ Formaldehyde } \\
\hline Yes $(4.3)$ & 23.1 & 18.7 & 6.2 & 7.2 & 44.8 & 26.2 \\
\hline No $(95.7)$ & 25.7 & 17.8 & 5.8 & 7.2 & 43.5 & 25.8 \\
\hline \multicolumn{7}{|c|}{ Pesticides or herbicides } \\
\hline Yes (10.2) & 28.9 & 17.7 & 6.0 & 6.1 & 41.3 & $26.3^{\mathrm{a}}$ \\
\hline No $(89.8)$ & 25.3 & 17.9 & 5.8 & 7.3 & 43.7 & 25.8 \\
\hline \multicolumn{7}{|c|}{ Textile fibers or dust } \\
\hline Yes $(5.9)$ & 20.6 & 21.5 & 7.0 & 6.0 & 44.9 & 26.0 \\
\hline No $(94.1)$ & 25.8 & 17.7 & 5.8 & 7.2 & 43.5 & 25.8 \\
\hline \multicolumn{7}{|l|}{ Wood dust } \\
\hline Yes (11.1) & 23.2 & 20.2 & 6.5 & 6.3 & 43.9 & $26.3^{\mathrm{a}}$ \\
\hline No $(88.9)$ & 25.8 & 17.6 & 5.8 & 7.2 & 43.6 & 25.8 \\
\hline \multicolumn{7}{|c|}{ Ionizing radiation } \\
\hline Yes (5.7) & 24.6 & 17.7 & 6.2 & 7.2 & 44.4 & $26.4^{\mathrm{a}}$ \\
\hline No $(94.3)$ & 25.7 & 17.8 & 5.8 & 7.2 & 43.5 & 25.8 \\
\hline
\end{tabular}

${ }^{a}$ Exposed differs from unexposed, $\mathrm{p}<.05$. 
exposure to exhaust from either gasoline or diesel engines. This type of information could be important in planning analyses of potentially exposed groups. It shows, for example, that men exposed to asbestos are also more likely to smoke than men not exposed, and that asbestos-exposed smokers consume significantly more cigarettes per day than do nonexposed smokers. The largest difference in smoking rates was in men exposed to coal or stone dust.

All but one of the ten exposed groups exhibited higher smoking rates than did the unexposed. This important observation of a positive correlation between smoking and various exposures emphasizes the need to take special care to control for the potential confounding effect of smoking in morbidity or mortality studies of male workers.

Corresponding data for women are shown in Table VII. Asbestos-exposed women, amounting to $2 \%$ of the cohort, were more likely to be smokers, as with men. Taken as a whole, however, there are no drastic differences between the smoking patterns of the exposed compared with the unexposed, for any of the ten exposures.

\section{DISCUSSION}

The main goal of CPS-II is to study the influence of lifestyle and environmental variables on death rates in a very large population. To the extent that adequate numbers of subjects in specfic occupations or exposed to pertinent hazards can be identified, occupational studies can be expected to yield useful results. This approach proved useful, for example, in analysis of mortality among over 10,000 carpenters and joiners and other woodworkers [Stellman and Garfinkel, 1984], using data from the predecessor study, CPS-I.

Because of the large number of ancillary variables solicited in the baseline questionnaire, it is easy to control not only the usual confounding factors, such as age and socioeconomic status, but other important factors commonly neglected in occupational mortality studies, such as diet and medication use.

Nevertheless, the most efficient type of occupational study is one which focuses on a specific industry. It is obvious that CPS-II can adequately "cover" only a limited number of specific occupations-namely, those with large numbers of employees. Furthermore, some occupational titles, such as "manager," do not indicate specific industries and must be considered at best socioeconomic indicators, not true occupations.

While the companion NIOSH study might at first seem free of this drawback, it must be recalled that the basic data from that cross-sectional survey comes by weighting responses from representative sampling units which may in fact be extremely few in number. Thus, only a very small number of individuals have actually contributed data to the occupation "plumber."

The smoking distributions are presented in Tables IV-VII without age adjustment. Direct adjustment to the age distribution of the cohort, in decades, produced only trivial changes $(0.0-0.1 \%$ in most cases). On the other hand, there were substantial differences in smoking patterns between those currently employed in a given occupation and retirees from that occupation (ie, subjects for whom the source of occupation was Q1 compared to those for whom it was Q2). Table VIII illustrates, for several occupations, that the rank order of occupations according to percent of 
TABLE VII. Percent Distribution of Smoking Habits of Women According to Occupational Exposures (Percent Exposed or Not Exposed Shown in Parentheses)

\begin{tabular}{|c|c|c|c|c|c|}
\hline \multirow[b]{3}{*}{$\begin{array}{l}\text { Exposed to } \\
(\%)\end{array}$} & \multicolumn{4}{|c|}{ Percentage of } & \multirow{3}{*}{$\begin{array}{c}\text { Average no. } \\
\text { cigarettes } \\
\text { smoked } \\
\text { daily by } \\
\text { current } \\
\text { smoker } \\
\text { (c/day) }\end{array}$} \\
\hline & \multirow{2}{*}{$\begin{array}{c}\text { Never } \\
\text { smoked } \\
\text { regularly }\end{array}$} & \multicolumn{2}{|c|}{$\begin{array}{c}\text { Current smoker of } \\
\text { cigarettes }\end{array}$} & \multirow{2}{*}{$\begin{array}{c}\text { Former } \\
\text { smoker } \\
\text { of } \\
\text { cigarettes }\end{array}$} & \\
\hline & & $\begin{array}{l}1-20 \\
\text { daily }\end{array}$ & $\begin{array}{l}21+ \\
\text { daily }\end{array}$ & & \\
\hline \multicolumn{6}{|l|}{ Asbestos } \\
\hline Yes $(2,0)$ & 51.8 & 14.7 & 6.3 & 27.2 & $21.2^{\mathrm{a}}$ \\
\hline No $(98.0)$ & 53.7 & 15.8 & 6.2 & 24.3 & 20.4 \\
\hline \multicolumn{6}{|c|}{ Chemicals or coal tar pitch } \\
\hline Yes $(7.4)$ & 50.1 & 16.7 & 7.6 & 25.6 & $21.5^{\mathrm{a}}$ \\
\hline No $(92.6)$ & 53.9 & 15.8 & 6.1 & 24.2 & 20.4 \\
\hline \multicolumn{6}{|c|}{ Coal or stone dust } \\
\hline Yes $(2.2)$ & 51.5 & 16.2 & 7.1 & 25.2 & $21.5^{\mathrm{a}}$ \\
\hline No $(97.8)$ & 53.7 & 15.8 & 6.2 & 24.3 & 20.4 \\
\hline \multicolumn{6}{|c|}{ Gasoline or diesel exhaust } \\
\hline Yes $(8.9)$ & 51.0 & 15.3 & 6.7 & 27.0 & $20.9^{\mathrm{a}}$ \\
\hline No (91.1) & 53.9 & 15.9 & 6.1 & 24.1 & 20.4 \\
\hline \multicolumn{6}{|l|}{ Dyes } \\
\hline Yes (3.7) & 53.5 & 16.4 & 6.0 & 24.1 & 20.4 \\
\hline No $(96.3)$ & 53.7 & 15.8 & 6.2 & 24.3 & 20.4 \\
\hline \multicolumn{6}{|c|}{ Formaldehyde } \\
\hline Yes (2.9) & 48.2 & 16.9 & 7.1 & 27.8 & 21.0 \\
\hline No $(97.1)$ & 53.8 & 15.8 & 6.2 & 24.2 & 20.4 \\
\hline \multicolumn{6}{|c|}{ Pesticides or herbicides } \\
\hline Yes $(4.1)$ & 54.8 & 13.4 & 6.4 & 25.3 & $21.4^{\mathrm{a}}$ \\
\hline No $(95.9)$ & 53.6 & 15.9 & 6.2 & 24.3 & 20.4 \\
\hline \multicolumn{6}{|c|}{ Textile fibers or dust } \\
\hline Yes (5.4) & 56.7 & 15.8 & 5.7 & 21.8 & 20.5 \\
\hline No $(94.6)$ & 53.6 & 15.8 & 6.2 & 24.4 & 20.4 \\
\hline \multicolumn{6}{|l|}{ Wood dust } \\
\hline Yes (1.9) & 53.3 & 16.4 & 7.3 & 23.1 & $21.5^{\mathrm{a}}$ \\
\hline No $(98.1)$ & 53.7 & 15.8 & 6.2 & 24.3 & 20.4 \\
\hline \multicolumn{6}{|c|}{ Ionizing radiation } \\
\hline Yes (4.5) & 46.3 & 17.7 & 6.9 & 29.1 & 20.3 \\
\hline No $(95.5)$ & 53.9 & 15.7 & 6.2 & 24.2 & 20.5 \\
\hline
\end{tabular}

${ }^{\mathrm{a}}$ Exposed differs from unexposed, $\mathrm{p}<.05$.

nonsmokers, for example, was practically unaltered whether the information source was Q1 (current occupation) or the composite variable "Job." Minor alterations occurred in this ordering when only Q2 was used (last job if retired), as this is based upon much smaller numbers of subjects. Differences in smoking distributions by retirement status proved to be almost entirely age-related. The age-specific distributions are not presented here in the interest of space. The authors will be glad to make age-occupation-specific smoking distributions available to interested readers upon request.

Examination of smoking patterns in different groups is a fascinating endeavor which can lead to important insights concerning how to design and analyze occupa- 
TABLE VIII. Percentage of Nonsmokers in Selected Occupations, According to Retirement Status (Males)

\begin{tabular}{lcc} 
& \multicolumn{2}{c}{ Percentage of } \\
\cline { 2 - 3 } Occupation & $\begin{array}{l}\text { Currently } \\
\text { employed }\end{array}$ & Retired \\
\hline Farmer & 40.8 & 31.5 \\
Teacher & 35.8 & 32.4 \\
Doctor & 32.8 & 21.8 \\
Woodworker & 24.9 & 19.8 \\
Manager & 23.3 & 20.1 \\
Electrician & 22.5 & 19.7 \\
Maintenance & 21.7 & 22.2 \\
Driver & 19.6 & 15.8 \\
\hline
\end{tabular}

tional studies of health effects, especially morbidity and mortality. It is not, however, a substitute for the analysis itself. Specific occupational groups tend to have characteristic smoking patterns. To the extent that such patterns differ from those in the reference population for an epidemiological study, the possibility of confounding must be dealt with.

The data presented here represent only an initial approach to what could become a far more detailed analysis. For instance, two variables which have not yet been examined in detail are years of exposure to specific hazards and personal history of serious illness. It might be important to restrict years of exposures to some lower limit, say 15 years, in order to emphasize long-term exposures, or to exclude "susceptible" workers who leave certain jobs because of adverse responses. Similarly, history of illness is important because of the healthy survivor effect, which is affected by smoking as well as by exposure to hazardous substances.

The most straightforward way of dealing with smoking is simply to measure it and condition analyses upon such measurements. Sometimes circumstances render such measurement impractical or impossible, particularly with historical data, data based upon death certificates, or data "contributed" by small units from a large industry. In such cases the best one can do is to examine smoking patterns of populations similar to those under investigation, and, if possible, choose a reference population which has smoking patterns similar to those of the study group. In such cases, confounding by smoking is likely to be less important than other sources of bias which may be dealt with more directly [Stellman, 1987].

In the end, however, deep analysis of the baseline data such as we have presented here is useful only insofar as it provides insights and hypotheses for analysis of health effects themselves.

\section{REFERENCES}

Brackbill R, Frazier T, Shilling S (1988): Smoking characteristcs of US workers, 1978-1980. Am J Med 13:5-41.

Garfinkel L, Stellman SD (1986): Cigarette smoking among physicians, dentists, and nurses. CA 36:39.

Stellman SD (1987): Confounding. Prev Med 16:165-182.

Stellman SD, Garfinkel L (1984): Cancer mortality among woodworkers. Am J Ind Med 5:343-357.

Stellman SD, Garfinkel L (1986): Smoking habits and tar levels in a new American Cancer Society prospective study of 1.2 million men and women. JNCI 76:1057-1063. 
Stellman SD, Stellman JM (1981): Women's occupations, smoking, and cancer and other diseases. CA 31:29-43.

\section{APPENDIX I. OCCUPATIONAL TITLES INCLUDED IN JOB CATEGORIES IN THE} TABLES

Aide: Teacher's, School, Library, Day-Care Worker, Child-Care Worker Assembler (In Factory)

Automotive, Auto Mechanic, Repair, Service Station, Gas Station Attendant

Banking, Bank Appraiser, Broker, Loan Officer, Teller

Beautician, Cosmetologist, Barber

Bookkeeper, Accountant

Civil Service, Government Worker (Federal, State, Local)

Clergy, Rabbi, Minister, Priest

Data Entry or Key Operator, CRT Operator, VDT Operator, PBX Operator

Domestic Service, Maid, Housekeeper

Driver, Truck Driver, Deliveryman, Routeman, Bus Driver, Taxi Driver

Executive, President, Vice President

Farmer, Farmhand, Farm Laborer, Rancher, Fisherman

Food Preparation, Food Service, Cook, Baker, Butcher, Chef

Law Enforcement, Police, Detective, Guard, Night Watchman, FBI Agent

Lawyer, Judge

Machinist, Machine Operator

Maintenance, Maintenance Man, Janitor, Handyman, Custodian

Nurse, RN, LPN, Male Nurse

Office Clerical, Secretary, Typist, Receptionist, Clerical Worker

Other Hospital Worker, Nurse's Aide, Orderly, Porter, Paramedic

Pharmacist, Chemist, Mortician, Funeral Director

Photographer, Lithographer, Printer

Postal Service, Postman, Mailman, Letter Carrier

Real Estate, Agent, Broker, Insurance Agent, Insurance Broker

Sales, Clerk, Retail, Store, Cashier

Sewer, Stitcher, Textile Worker, Seamstress, Upholsterer

Steel Mill Operative, Steel Worker

Teacher, School Superintendent, School Administrator, Professor, Dean, Principal, Librarian

Technician, Laboratory Worker, X-ray

Telephone Operator, Telegraph Operator

Woodworker, Carpenter, Furniture or Cabinet Maker, Repair, Refinisher, Logger, Saw Mill or Lumber Worker

Writer, Editor, Publisher, Newsman, Newspaper Person, Copywriter, Advertising Person 